\title{
Enhancing existing formal home care to improve and maintain functional status in older adults: Protocol for a feasibility study on the implementation of the Care to Move (CTM) programme in an Irish healthcare setting
}

\author{
N. Frances Horgan', Vanda Cummins ${ }^{1,2}$, Frank Doyle ${ }^{3}$, Maria 0'Sullivan ${ }^{4}$, Rose Galvin ${ }^{5}$, Elissa Burton ${ }^{6}$, \\ Jan Sorensen ${ }^{7}$, Dawn A. Skelton ${ }^{8,9}$, Bex Townley ${ }^{9}$, Debbie Rooney ${ }^{10}$, Gill Jackson ${ }^{10}$, Lauren Swan ${ }^{4}$, \\ Austin Warters ${ }^{11}$
}

'School of Physiotherapy, Royal College of Surgeons in Ireland (RCSI), Ireland; ${ }^{2}$ Primary Care Physiotherapy Services CHO9, Health Service Executive (HSE); ${ }^{3}$ Division of Population Health Sciences (Psychology), Royal College of Surgeons in Ireland (RCSI), Ireland; ${ }^{4}$ Department of Clinical Medicine, Trinity College Dublin (TCD), Ireland; ${ }^{5}$ School of Allied Health, University of Limerick (UL), Ireland; ${ }^{6}$ School of Physiotherapy and Exercise Science, Curtin University, Australia; ${ }^{7}$ Health Outcomes Research Centre (HORC), Royal College of Surgeons in Ireland (RCSI), Ireland; ${ }^{8}$ School of Health and Life Sciences, Glasgow Caledonian University, United Kingdom; ' ${ }^{L}$ Later Life Training, United Kingdom; ${ }^{10}$ North Dublin Home Care (NDHC), Ireland; ${ }^{11}$ Older Person Services CHO9, Health Service Executive (HSE), Ireland

All published work is licensed under Creative Common License CC BY-NC-SA 4.O (Attribution-NonCommercial-ShareAlike)

\begin{abstract}
An increasing ageing population leads to greater demand for care services to help maintain people in their own homes. Physical activity programmes have been shown to improve older adults' functional capacity, enabling the older adult to live independently and maintain functional status. There has been a lack of quality research conducted around physical activity within the landscape of home care services. We describe a feasibility study of implementing the Care to Move (CTM) programme in older adults receiving low-level home care. A Phase 1 mixed-methods feasibility study design will explore the recruitment, attrition, retention, costs to deliver and data loss. It will also explore the acceptability and impact of the CTM programme on older adults and thematic analysis of data collected from older people, home care workers and relevant stakeholders through use of semi-structured interviews and focus groups. We will measure functional status and fall outcomes in older adults receiving low levels of home care, facilitating this population to continue living independently at home and providing data currently not known around this group.
\end{abstract}

Keywords: Community-dwelling, Feasibility, Home care, Older person, Physical activity-based

\section{Introduction}

Ireland, like many other countries, has seen a steady increase in life expectancy and has an ageing population. Projections indicate that by 2021 the number of older people will have grown by 200,000 and the numbers over 65 will reach $1.4 \mathrm{~m}$ by 2046'. Specifically, the Economic and Social Research Institute (ESRI) project a $94.0 \%$ increase in the number of people aged 80 years and older nationally between $2015-2030^{2}$. This marked increase will be relevant in areas such as Dublin North City where the population aged 80 years and over currently remains higher than the national average at $3.2 \%$.
Bex Townley and Dawn A. Skelton are Directors of Later Life Training Ltd, a not for profit company delivering training in exercise delivery with older people, including the Care To Move Approach. The remaining authors declare no conflict of interest.

Corresponding author: Professor Frances Horgan, School of Physiotherapy, Royal College of Surgeons in Ireland, 123 St Stephen's Green, Dublin 2, Ireland

E-mail: fhorgan@rcsi.ie

Edited by: Yannis Dionyssiotis

Accepted 6 February 2020 
While formal home care has been identified as one key strategy to support independent living, the ability of social and health care funding to keep pace with growing demand has come under scrutiny in recent years as those receiving home care services are increasing in numbers and have varying levels of support required ${ }^{4,5}$. Between 2000 and 2010, there has been a fourfold increase in the number of people in receipt of home care services ${ }^{5}$. Currently, $97 \%$ of formal home care is financed by the Irish state ${ }^{6}$. The current service configuration poses challenges in the trajectories of care.

The concept of frailty is increasingly used to describe the situation of a large proportion of older people receiving home care. They are at risk of being unable to recover from adverse events, such as falls and their care needs may escalate over time ${ }^{7}$. Those transitioning into frailty are particularly sedentary and avoid activity often for fear of falling ${ }^{8,9}$. A recent internal review of around 1,300 Irish low level home care service users showed increasing age and a higher frequency of care hours to be significantly associated with greater levels of frailty and $75 \%$ of home care recipients assessed, were categorised as vulnerable, mildly frail or moderately frail indicating the relevance of an intervention aimed at this group ${ }^{3}$.

There has been strong interest in developing innovative and cost-effective interventions to support older people living in their homes and, in turn, to reduce demand on acute hospital services and residential care provision ${ }^{10}$.

There has been extensive research into structured exercise programmes for frailer older people or those with sarcopenia11-13. However, uptake and adherence to such interventions is often poor ${ }^{1-13}$. Home care is also an important arena to address falls prevention and QOL, but this vulnerable group of older adults is underrepresented in health research ${ }^{14}$. One recent study of a falls prevention exercise programme based on the Otago Exercise Programme (OEP) significantly improved physical function, Health Related Quality of Life (HRQOL) and balance in older adults receiving home care but was cost intensive ${ }^{14}$. Integrating strength and balance activities into daily life activities has shown better adherence but there are less studies in those receiving care ${ }^{15}$.

Research around structured exercise programmes has been completed in different groups of community-dwelling older people, however few studies have focused on the older population receiving formal home care. A recent systematic review of physical activity programmes for older people receiving home care identified few consistencies and recommended the need for more evidenced based trials investigating physical activity promotion programmes tailored for this group of older adults ${ }^{16,17}$.

Research, specifically with home care clients, has shown that older people prefer integrated lifestyle exercise and being physically active through activities they enjoy, rather than more structured exercise programmes ${ }^{18}$. Through the Care To Move (CTM) programme participants are encouraged to do more 'movement' associated with self-care activities and, with support, integrate some strength and balance activities into their day as opposed to a prescribed set of exercises conducted for a set amount of time ${ }^{19}$. CTM is a whole workforce approach, because its primary aim is to bring consistency (of language, correct messages) to teams delivering packages of care or those regularly engaging with older people in their homes. CTM provides a series of consistent 'movement prompts' to use and embed into existing movements of daily living and offers a series of key messages to communicate during all interactions about sitting and moving more with a view to encouraging and empowering older people to make different decisions in the longer term to better contribute to their health, well-being, confidence and independence. The purpose of intervening in the group is to delay functional decline, thereby maintaining independence and reducing the need for increased formal home care. Although there have been promising local service evaluations of CTM, there has been no formal research published.

The aim of this study is to investigate the feasibility and acceptability of implementing the CTM programme in older adults living in the community who are receiving low-level home care. Through enhancing home care services, this research will aim to evaluate a more sustainable approach to ageing in place as supported by current strategies for health and well-being in Ireland. By incorporating older adults receiving low-level home care this study is attempting to reduce rates of functional decline in this vulnerable older group. If functional status can be maintained or improved it may delay or prevent increased use of formal home care.

\section{Materials and methods}

\section{Study design}

Phase 1 Feasibility study exploring the potential for a future randomised controlled trial (RCT) of the Care to Move (CTM) programme in the context of a community physiotherapy service with older service users receiving lowlevel home care support. We will apply Bowen's framework for feasibility studies ${ }^{20}$ the recent guidelines for reporting non randomised feasibility studies ${ }^{21}$ and will follow the Medical Research Council (MRC) framework for complex interventions ${ }^{22}$.

\section{Participants and recruitment}

Recipients of low-level home care will be recruited from a not-for-profit home care company located in Dublin North City. Care managers, supervisory staff and home care workers will review and screen a list of all service users based on inclusion and exclusion criteria. Inclusion Criteria: Service users will be eligible to participate if they are aged 65 years or older, have a Clinical Frailty Score ${ }^{7}$ of 6 or less, have fallen at least once in the last year, receive $\leq 5$ hours of home care a week and are independently mobile (with or without a walking aid). Exclusion Criteria: Service users will be excluded 
if they have moderate to severe cognitive impairment, have any unstable clinical conditions, are receiving end of life care, or would be unable to follow instructions about exercising, moving or being more physically active, safely.

\section{Procedure}

Eligible service users will be provided with a study invitation letter and participant information sheet and will receive a follow-up call within a week to establish if they would like to participate. Following identification of suitable participants, a face-to-face meeting will be arranged with the research physiotherapist to discuss the project. Participants will be given up to seven days between receipt of the study information and being requested to give written permission. Withdrawal from the study will not impact on the level of home care received. Subsequent home visits will be arranged and completed by a research physiotherapist to obtain written consent and to provide any further information regarding the study. Participants will then receive the CTM intervention for six months. Assessments will be completed during home visits at baseline, after 8 weeks of the intervention and at 6 months by a research physiotherapist.

\section{Description of Care To Move (CTM) intervention}

We will report the CTM intervention according to the TIDiER Guidelines $^{23}$. CTM provides a series of consistent 'movement prompts' to use and embed into existing movements of daily living and offers a series of key messages for care staff to communicate during all interactions about sitting and moving more with a view to encouraging and empowering older people to make different decisions in the longer term to better contribute to their health, well-being, confidence and independence. CTM is not a structured exercise programme but is specifically designed to give home care workers and volunteers confidence to have empowering and motivating interactions with clients, patients and service uses across any setting or service working with older people. CTM training was originally designed for a domiciliary enablement service in South Wales and following extensive observation of care visits and discussion with care service leads and therapy leads the training outcomes were designed in recognition of the missed opportunities observed, and to address a clear unmet training need for non-qualified workforce (who have the most opportunities for interaction with service users/ patients/older people).

In this study the identified staff (home care workers) trained in CTM (CTM Motivators) will complete a two day CTM course. The CTM course has three key themes/approaches; Communication skills to have purposeful conversations about movement (providing a structured framework); A series of targeted, specific movements and prompts (for key movements already being performed as part of the usual package of care, daily living); Where applicable, motivating and empowering older people to carry out home exercise programmes prescribed by therapy services. Key members of the team will also be trained as CTM Key Trainers (cascade training for future CTM Motivators) for sustainability. The CTM participants will be encouraged to undertake movements specifically prescribed to improve balance or increase strength. These activities will be embedded within everyday activities; so that the movements can be done several times during the day rather than a prescribed set of exercises conducted for a set amount of time. The duration of the СTM intervention will be eight weeks. During the initial eight weeks, the research physiotherapist will work with the home care worker (i.e. CTM Motivator) and the participant (i.e. home care client) to demonstrate how the movements can be completed safely and effectively over 3 visits. A fourth follow-up visit will then be completed by the research physiotherapist after 6 months to complete the final assessment. Over the study period, it will be the role of the home care worker to encourage and prompt the participant to engage in the CTM programme on their home care visits, which will occur at least once a week. The TiDIER ${ }^{23}$ standardised reporting guidelines for intervention description and replication will be followed to ensure the standardised conduct and reporting of the CTM programme (Appendix 1).

\section{Health behaviour change}

During the delivery of training in CTM to the home care staff and key trainers, the CTM intervention was mapped against Behaviour Change Techniques (BCTs) from the COM-B Taxonomy ${ }^{24}$. We will conduct interviews with the study participants, and home care workers. The interviews will be grounded in social-cognitive theory ${ }^{25}$, exploring the theoretical proximal determinants of behaviour (e.g. self-efficacy, outcome expectancies, self-regulation). This theory will also be used in the actual intervention, which will allow for appropriate process evaluation ${ }^{26}$ to produce a logic model for implementation that can be tested in a later study. Home care workers will be key to delivering CTM, by motivating and encouraging participants beyond the collaboration with the physiotherapist. We will look at the home care organisation documents, to identify if participants' goals change over time (i.e. did they show progression?) so as to document the participant adherence to the movements recommended over time.

\section{Outcome measures}

Primary outcomes: Our primary outcomes will be based on the feasibility of the CTM intervention and data collection across the study period. These will include: number of home care clients that are recruited (recruitment), that provide data at 8 weeks and 6 month follow-up (retention), and show engagement with CTM and progression over time using care documentation (adherence). The primary outcome of the future definitive RCT will be decided by the responsiveness to change, participant burden and participant feedback from this study. We will document data loss in the questionnaires and tests within the secondary outcome measures and document any adverse events related to the CTM intervention. 
Secondary Outcomes: All participants will be assessed at baseline, after 8 weeks and 6 months. The main secondary outcome will be Timed Up and Go (TUG) test ${ }^{27}$. We have a series of validated questionnaires to assess: Frailty ${ }^{7}$ (Rockwood); level of physical activity - PhoneFITT ${ }^{28}$; Nottingham Extended Activities of Daily Living (NEADL) scale $^{29}$; Lower body strength, as measured by performance of 30-second chair stand test ${ }^{30}$. Balance confidence will be assessed with the shortened 10-item Activity specific Balance Confidence (ABC) scale ${ }^{31}$, and the CONFBal - a 10item falls self-efficacy scale ${ }^{32}$. Quality of life will be assessed using the SF-36 and EuroQOL EQ5D-5L questionnaires ${ }^{33}$. For social cognitive theory (SCT), a validated SCT scale will be used ${ }^{34}$. We will produce a logic model for implementation that can be tested in a future study. We will explore the capacity to deliver the intervention in the context of community physiotherapy services working in partnership with a home care organisation, examine delivery (fidelity) and compliance of the intervention. Participants will be asked to complete a weekly report to be collected by the home care worker in which they will monitor any falls or major health changes and health care use. Participants will be given a weekly calendar to tick each day they performed an activity during the study period.

\section{Health economic evaluation}

We will examine the implementation and running cost of the CTM-programme, assess the health economics outcomes in terms of improved functional ability and healthrelated quality of life (including quality-adjusted life years), and down-stream use and cost of health and social care resources. A model-based cost-effectiveness analysis will be calibrated with best available data (including data from the prospective data collection) and applied to assess the cost-effectiveness of scenarios with CTM implemented at different scales and in different settings. The model will further be explored in a Value-of-Information analysis to describe the potential benefit from future research and in particular provide information about the optimal sample size of future clinical trials of CTM interventions ${ }^{35}$.

\section{Sample size}

This study is a feasibility study and so no formal power calculation has been carried out. Part of this feasibility study will assess whether enough participants can be recruited and retained in the study and outcome data generated to inform the potential for a future Phase Il study. We have therefore not powered the study for specific outcomes but aim to recruit 40 participants with the goal of retaining 30 to follow-up. The sample size was deemed to give sufficient insights into the intervention implementation and data collection process, and sufficient data to conduct meaningful analysis and to be relevant for sample size calculation for a future randomised study. The attrition rate varies between $15 \%$ and $30 \%$ as demonstrated by previous physical activity studies ${ }^{36-38}$.

\section{Data analysis}

Baseline demographic and outcome variables will be described at all assessment times. Information on missing or incomplete data from all outcome measures will be reviewed. Although not powered for effectiveness, tests will be completed with a 0.05 level of significance. To consider trends in outcome measures, the change in scores from baseline to T2 to T3 in the various outcome measures will be calculated. The data will be inputted into Stata version 16 (Texas, USA). Descriptive statistics will be primarily used. We will conduct focus groups and interviews to ascertain the views and experiences of participants and home care staff. Open-ended responses from the qualitative interviews and focus groups will be analysed thematically using an approach described by Miles and Huberman ${ }^{39}$. The health economic costs of the programme as well as the costs of other health and social care will be described. A decision analytic model will be developed using data from the performed data collection and supplemented with data from other sources. Different scenarios for service organisation and the effectiveness will be described using this model and their relative cost-effectiveness in comparison with no CTM program will be calculated. Sensitivity analysis will show the cost-savings and improved effectiveness that should be achieved in order for that intervention to be cost-effective and what additional data collection or quality control will be needed in a Phase II study.

\section{Ethical considerations}

Ethical approval has been granted by the Royal College of Surgeons in Ireland Research Ethics Committee (REC -2018:1489).

\section{Acknowledgments}

This study is funded by a Health Research Board Applied Partnership Award 2017 (HRB APA-2017-013). At the time of submission the status of the study is "currently recruiting'.

\section{Disclaimer}

Prof. Dawn Skelton serves as Co- Editor in Chief in the JFSF. The manuscript underwent peer review process by independent experts.

\section{References}

1. CSO. Population and Labour Force Projections 20172051. 2017 [viewed 27November 2019] Available from: https://www.cso.ie/en/releasesandpublications/ep/p-plfp/ populationandlabourforceprojections2017-2051/index.html

2. ESRI, Wren M-A, Keegan C, Walsh B, ESRI, Bergin A, et al. Projections of demand for healthcare in Ireland, 2015-2030: First report from the Hippocrates Model ESRI; 2017 Oct [viewed 22May 2019]. Available from: http://www.esri.ie/publications/projections-ofdemand-for-healthcare-in-ireland-2015-2030-first-report-fromthe-hippocrates-model/

3. Kelly S, O Brien I, Smuts K, O'Sullivan M, Warters A. Prevalence of 
frailty among community dwelling older adults in receipt of low-level home support: a cross-sectional analysis of the North Dublin Cohort. BMC Geriatr 2017: 7(17):121.

4. Murphy C, Whelan B, Normand C. Formal home care utilisation by older adults in Ireland: Evidence from the Irish Longitudinal Study on Ageing, Health and Social Care in the Community 2015: 23(4): 408-418.

5. Timonen V, Doyle M, O'Dwyer C. Expanded, but not regulated: ambiguity in home-care policy in Ireland. Health and Social Care in the Community 2012: 20(3):310-318.

6. PA Consulting Group. Analysis of Irish Home Care Market. Irish Private Home Care Association, Dublin 2010.

7. Rockwood K, Howlett SE, MacKnight C, Beattie BL, Bergman H, Hébert R, Hogan DB, Wolfson C, McDowell I. Prevalence, attributes, and outcomes of fitness and frailty in community-dwelling older adults: report from the Canadian study of Health and Aging. J Gerontol A Biol Sci Med Sci 2004: 59(12): 1310-1317

8. Harvey JA, Chastin SF, Skelton DA. How Sedentary are Older People? A Systematic Review of the Amount of Sedentary Behavior J Aging Phys Act 2015: 23(3):471-487.

9. Harvey JA, Chastin SFM, Skelton DA. Breaking sedentary behaviour has the potential to increase / maintain function in frail older adults. Journal of Frailty, Sarcopenia and Falls 2018: 3(1):26-34.

10. Department of Health. Gov.ie Sláintecare Implementation Strategy. 2018. [viewed 25June 2019]Available from https://www.gov.ie/ en/campaigns/slaintecare-implementation-strategy/?referrer=/ slaintecare

11. Jadczak AD, Makwana N, Luscombe-Marsh N, Visvanathan R, Schultz TJ. Effectiveness of exercise interventions on physical function in community-dwelling frail older people: an umbrella review of systematic reviews. JBI Database System Rev Implement Rep 2018: 16(3):752-775.

12. Lopez P, Pinto RS, Radaelli R, et al. Benefits of resistance training in physically frail elderly: a systematic review. Aging Clin Exp Res 2018:30(8):889-899

13. Beaudart C, Dawson A, Shaw SC, et al. Nutrition and physical activity in the prevention and treatment of sarcopenia: systematic review. Osteoporos Int 2017: 28(6): 1817-1833.

14. Bjerk M, Brovold T, Davis JC, Skelton DA, Bergland A. Health-related quality of life in home care recipients after a falls prevention intervention: a 6-month follow-up. Age Ageing 2019: 48(2):213-219.

15. Weber M, Belala N, Clemson L, Boulton E, Hawley-Haque H, Becker C, Schwenk M. Feasibility and Effectiveness of Intervention Programmes Integrating Functional Exercise into Daily Life of Older Adults: A Systematic Review. Gerontology 20 18: 64(2):172-187.

16. Burton E, Lewin G, Boldy D. A Systematic Review of Physical Activity Programs for Older People Receiving Home Care Services. J Aging Phys Act 2015: 23(3): 460-470.

17. Burton E, Farrier K, Galvin R, Johnson S, Horgan NF, Warters A, Hill KD. Physical activity programs for older people in the community receiving home care services: systematic review and meta-analysis. Clin Interv Aging 2019: 6(14): 1045-1064.

18. Burton E, Lewin G, Boldy D. Physical activity preferences of older home care clients. International Journal of Older People Nursing. 2015: 10(3): 170-178.

19. Later Life Training UK [viewed 27November 2019] Available from https://www.laterlifetraining.co.uk/courses/care-move-ctm-course/

20. Bowen DJ, Kreuter M, Spring B, Cofta-Woerpel L, Linnan L, Weiner D, Bakken $S$ et al. How we design feasibility studies. Am J Prev Med 2009: 36(5):452-457.
21. Lancaster, G.A., Thabane, L. Guidelines for reporting non-randomised pilot and feasibility studies. Pilot Feasibility Stud 2019: 5:1 14.

22. Craig P, Dieppe P, Macintyre S, Michgie S, Nazareth I, Petticrew M et al. Developing and evaluating complex interventions: the new Medical Research Council Guidance. BMJ 2008: 337: 1655

23. Hoffmann TC, Glasziou PP, Boutron I, Milne R, Perera R, Moher D, Altman DG, et al. Better reporting of interventions: template for intervention description and replication (TIDieR) checklist and guide. BMJ 2014: 348:g1687.

24. Michie S, van Straten MM, West R. The behaviour change wheel: A new method for characterising and designing behaviour change interventions. Implement Sci 201 1:6:42.

25. Bandura A. Health promotion from the perspective of social cognitive theory. Psychology \& Health 1998: 13: 623-649.

26. Moore GF, Audrey S, Barker M, Bond L, Bonell C, Hardeman W, Moore L, O'Cathain A, Tinati T, Wight D, Baird J. Process evaluation of complex interventions: Medical Research Council guidance. BMJ 2015: 19:350:h1258.

27. Podsiadlo D, Richardson S. The Timed "Up and Go": A test of basic functional mobility for frail elderly persons. J Am Geriatr Soc 1991 : 39(2): 142-148.

28. Gill DP, Jones GR, GuangYong Z, Speechley M. The Phone-FITT: A brief physical activity interview for older adults. J Aging Phys Activity 2008: 16(3):292-315

29. Nouri FM, Lincoln NB. An extended activities of daily living scale for stroke patients. Clinical Rehabilitation 1987: 1:301-305.

30. Rickli R, Jones C. Functional fitness normative scores for communityresiding older adults, ages 60-94. J Aging Phys Activity 1999 7(2): 162-181

31. Powell LE, Myers AM. The Activities-specific Balance Confidence (ABC) Scale. J Gerontol A Biol Sci Med Sci 1995: 50(1):28-34

32. Simpson JM, Worsfold C, Fisher KD, Valentine JD. The CONFbal scale; a measure of balance - a key outcome of rehabilitation. Physiotherapy 2009: 95(2): 103-109.

33. Herdman M, Gudex C, Lloyd A, Janssen M, Kind P, Parkin D, Bonsel $G$, Badia X. Development and preliminary testing of the new five-level version of EQ-5D (EQ-5D-5L). Qual Life Res 2011 20(10):1727-1736.

34. Marcus BH, Selby VC, Niaura RS, Rossi JS. Self-efficacy and the stages of exercise behaviour change. Res Q Exerc Sport 1992 63(1):60-66.

35. Drummond M, Sculpher MJ, Torrance GW, O'Brian B, Stoddart GL. Methods for the evaluation of health care programmes. 3rd ed. Oxford: Medical Publications, 2005

36. Burton E, Lewin G, Clemson L, Boldy D. Determining the feasibility of a lifestyle activity program for inclusion in a restorative home care service: a pilot study. Activ Adapt Aging 2013: 38(2):79-93

37. Ota A, Yasuda N, Horikawa S, Fujimura T, Ohara H. Differentia effects of power rehabilitation on physical performance and higher-level functional capacity among community-dwelling older adults with slight degree of frailty. Journal of Epidemiology 2007 17(2):61-67

38. Johnson C, Myers A, Scholey L, Cyarto EV, Ecclestone N. Outcome evaluation of the Canadian Centre for Activity and Aging's home support exercise program for frail older adults. Journal of Aging and Physical Activity 2003: 11: 408-424.

39. Miles M, Huberman A. An Expanded Source Book: Qualitative data analysis (2nd edn). Thousand Oaks: Sage Publications, 1994 
Appendix 1. TIDieR (Template for Intervention Description and Replication) Checklist*:

\begin{tabular}{|c|c|c|c|}
\hline \multirow{2}{*}{$\begin{array}{l}\text { Item } \\
\text { number }\end{array}$} & \multirow[t]{2}{*}{ Item } & \multicolumn{2}{|c|}{ Where located * * } \\
\hline & & $\begin{array}{l}\text { Primary paper } \\
\text { (page or appendix } \\
\text { number) }\end{array}$ & Other + (details) \\
\hline & BRIEF NAME & & \\
\hline \multirow[t]{2}{*}{1.} & Care To Move (CTM). & $-10 \& 12$ & $\begin{array}{l}\text { https://www.laterlifetraining.co.uk/ } \\
\text { courses/care-move-ctm-course/ }\end{array}$ \\
\hline & WHY & & \\
\hline \multirow[t]{2}{*}{2.} & $\begin{array}{l}\text { CTM provides a series of consistent 'movement prompts' to use and embed into exisiting movements of daily living. The } \\
\text { aim is for home care recipients to move more and sit less. }\end{array}$ & -12 & $\begin{array}{l}\text { https://www.laterlifetraining.co.uk/ } \\
\text { courses/care-move-ctm-course/ }\end{array}$ \\
\hline & WHAT & & \\
\hline 3. & $\begin{array}{l}\text { Materials: CTM diary provided to participants by home support workers. The diary includes an information sheet, CTM plan } \\
\text { and CTM client record.. CTM Client Record for completion by the care staff which includes which ADL tasks client has agreed } \\
\text { to movement prompts and recommendations for continuation of practice of movements. }\end{array}$ & -12 & $\begin{array}{l}\text { https://www.laterlifetraining.co.uk/ } \\
\text { courses/care-move-ctm-course/ }\end{array}$ \\
\hline 4. & $\begin{array}{l}\text { Procedures: On Client Record: At start of visit (tick-box): } \\
\text { - Your greeting had a 'movement' check } \\
\text { - Discussed 'how' they moved since last visit } \\
\text { - Discussed any previous successes } \\
\text { - Started planning for today's tasks with a key focus \& messages (Set up the task and review on completion of every task- } \\
\text { proactively encouraging feedback/staying engaged with the task) } \\
\text { During ADL Tasks (tick-box): } \\
\text { - Used 'Prepare to move' prompts regularly } \\
\text { - Used prompts to improve active posture In sitting } \\
\text { - Used prompts to help with bum shuffle } \\
\text { - Used prompts to help mobility/circulation } \\
\text { - Used prompts to help stand up or sit down } \\
\text { - Encouraged them to 'power up' through heels and legs } \\
\text { - Reminded to pause on stand } \\
\text { - Reminded to foot pedal before walking } \\
\text { - No talking when walking or changing direction } \\
\text { - Used prompts to help ADL's in standing: heel raises/ knee bends } \\
\text { Before Leaving (tick-box): } \\
\text { - Reviewed any movement successes } \\
\text { - Discussed movement plan for next visit and left a 'seed of thought' } \\
\text { Recommended they continue practicing prompts during tasks: } \\
\text { - In bed } \\
\text { - In sitting } \\
\text { - When dressing/ washing } \\
\text { - When standing up } \\
\text { - When toileting } \\
\text { - When walking/ turning } \\
\text { - Other: }\end{array}$ & -12 & $\begin{array}{l}\text { https://www.laterlifetraining.co.uk/ } \\
\text { courses/care-move-ctm-course/ }\end{array}$ \\
\hline
\end{tabular}




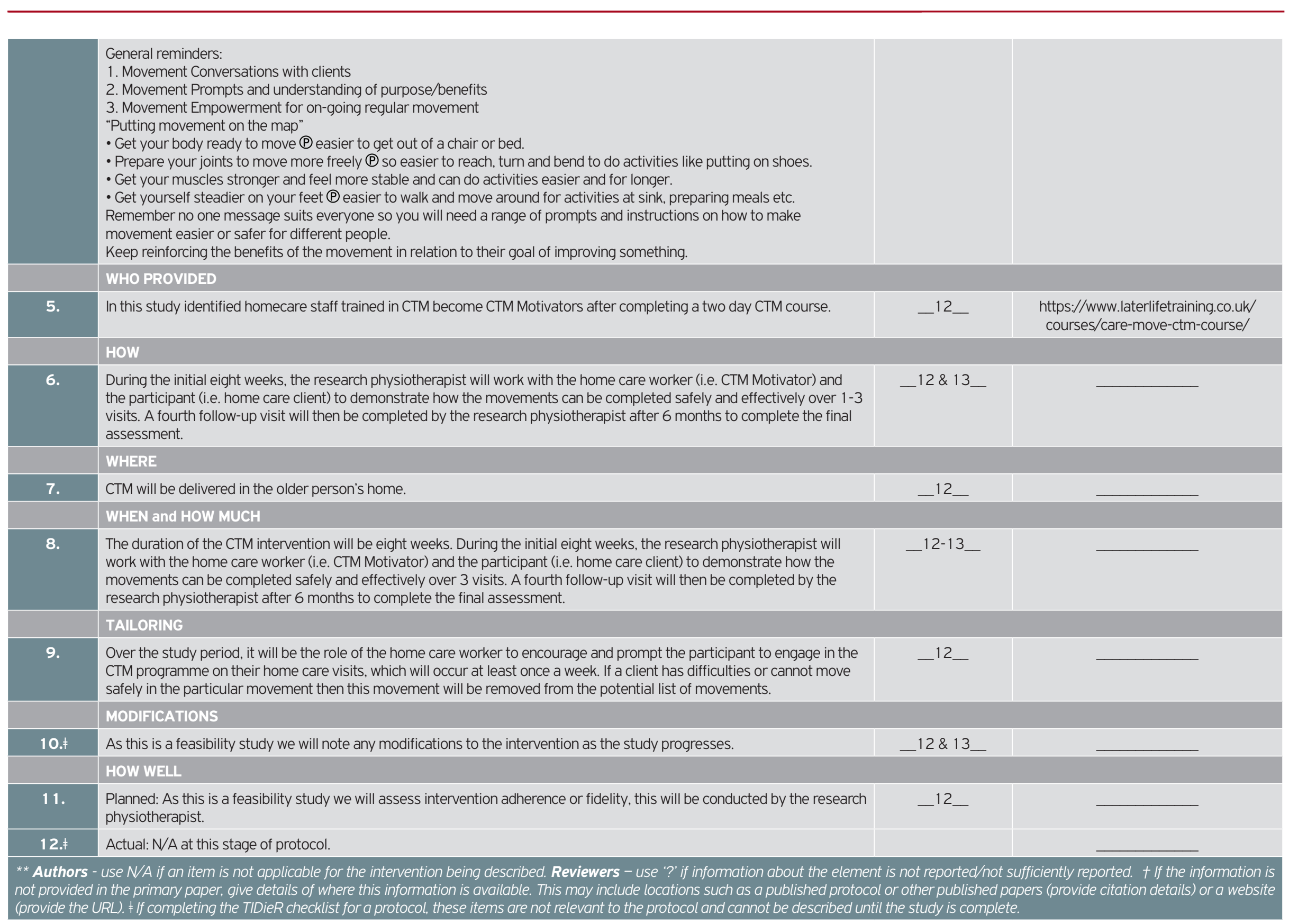

